\title{
Statyba
}

\section{ERGONOMIC ASSESSMENT OF MANUAL BUILDING WORK ASSOCIATED WITH LIFTING TASKS}

\section{K. A. Kaminskas PhD}

To cite this article: K. A. Kaminskas PhD (2001) ERGONOMIC ASSESSMENT OF MANUAL BUILDING WORK ASSOCIATED WITH LIFTING TASKS, Statyba, 7:5, 370-373, DOI: 10.1080/13921525.2001.10531756

To link to this article: https://doi.org/10.1080/13921525.2001.10531756

曲 Published online: 30 Jul 2012.

Submit your article to this journal $\pi$

LII Article views: 117 


\section{RANKŲ DARBO STATYBOJE, KELIANT MAŽAGABARIČIUS SUNKIUS ELEMENTUS, ERGONOMINIS VERTINIMAS}

\section{K. A. Kaminskas}

\section{Vilniaus Gedimino technikos universitetas}

\section{Ivadas}

Nors per praëjusius dešimtmečius vyko spartus pramoninio darbo automatizavimas, tačiau sužalotu darbininkų skaičius atliekant kèlimo ir gabenimo darbus metai iš metụ yra didelis.

Troupas ir Edwardsas [1] nurodo, kad 69\% nugaros žemutinés dalies sužalojimu priežastis yra pertempimas. Didžioji dalis šiu sužalojimu, t. y. 51\%, atsiranda atliekant kèlimo, nešimo, laikymo rankose ir metimo darbus.

Tiriant darbininko, rankomis atliekančio kèlimo darbus, pozą, atsižvelgiama i daugeli parametru, tokiu kaip elektromiografija (EMG), didžiausias priimtinas krovinio svoris, energijos sąnaudos ir kt. Pagal biomechaninius, fiziologinius ir psichofiziologinius parametrus pirmenybẻ teikiama darbui, kai keliama pasilenkus, palyginti su kélimu pritūpus [2].

Direktyvoje 90/269/EEB ir ją atitinkančiame Lietuvos Respublikos teisès akte [3] numatyti tam tikri kroviniu kèlimo, laikymo ir nešimo darbu reikalavimai. Kuriant ir tobulinant ergonomines priemones bei metodus svarbu prieš tai atlikti tiriamuosius darbus. Tokio pobūdžio tyrimai statybos industrijoje iki šiol nebuvo atliekami. Ypač svarbu nustatyti, kaip ergonominèmis priemonemis galima sumažinti darbininku, rankomis atliekančių kélimo darbus, nugaros žemutinès dalies apkrovima.

\section{Tyrimo tikslas ir metodai}

Pagrindinis tyrimo tikslas yra parodyti, kaip ergonominiai sprendimai ir naudojamos ergonomines priemonès mažina riziką susižaloti nugara, kai rankomis keliami mažagabaričiai sunkūs elementai.

Tyrimui buvo pasirinkti granito plokščiu klojejjai, dirbantys Vilniaus Katedros aikštèje ( 1 ir 2 pav.), po- rètojo silikato blokeliu mūrininkai, statantys Biznio centrą Vilniaus gatveje ( 3 pav.) ir UAB „Silikatas" plytu krovèjai, dirbantys su plytụ krašto nuskèlimo ịrenginiu (4 pav.).

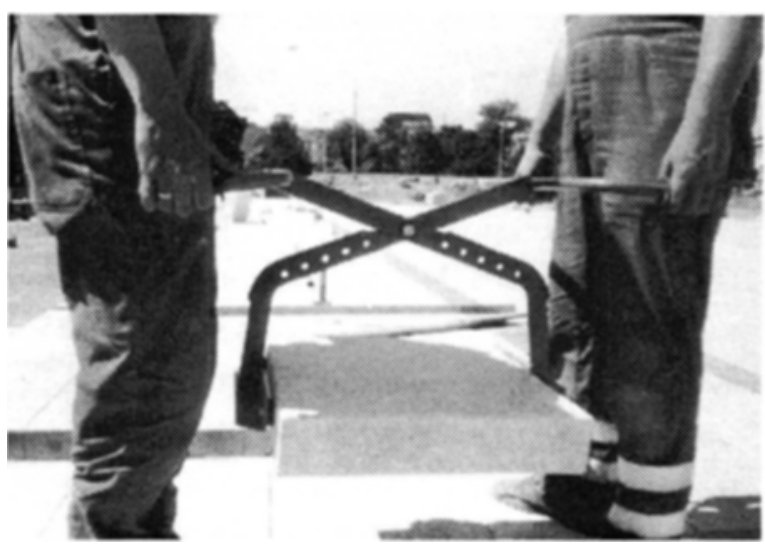

1 pav. Granito plokštès kèlimas mechaniniu kẻlikliu

Fig 1. Lifting granite plate by a mechanical device

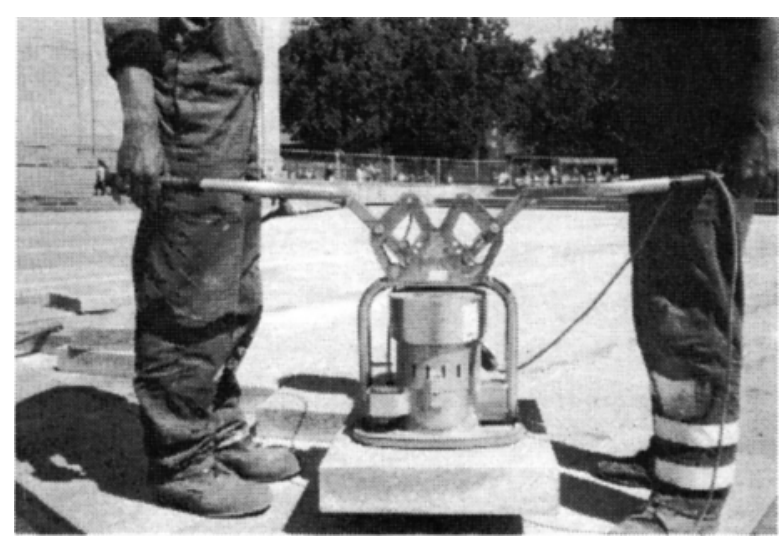

2 pav. Granito plokštès kèlimas pneumatiniu kélikliu

Fig 2. Lifting granite plate by a pneumatic device 


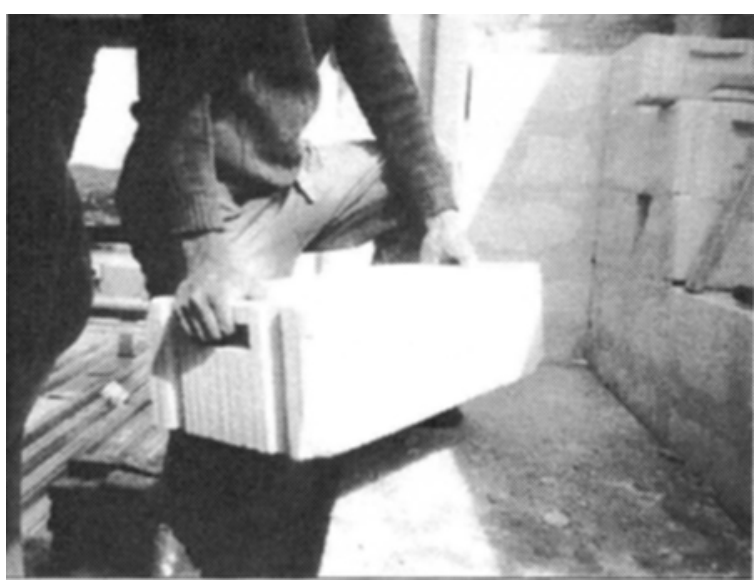

3 pav. Porétojo silikato blokelių kélimas rankomis

Fig 3. Manual lift method for porous silicate blocks

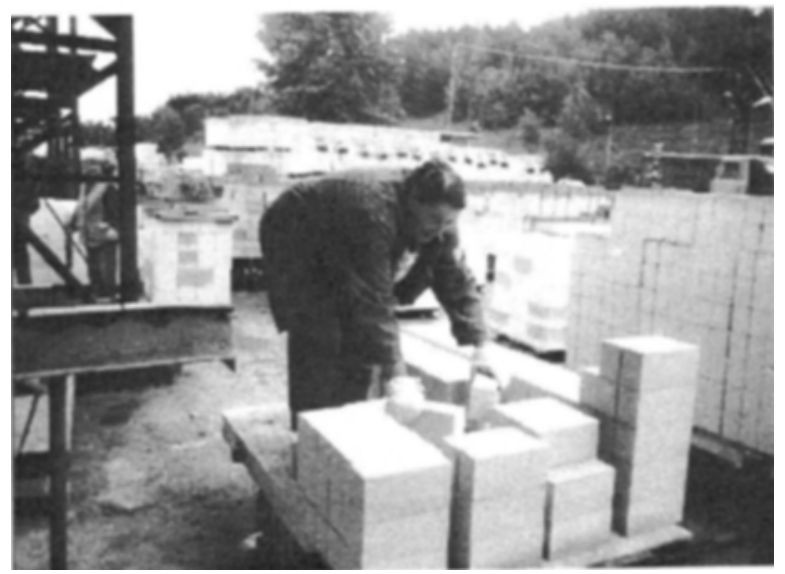

4 pav. Plytu perkrovejo poza

Fig 4. Working posture of a brick reloader

Tyrimui naudota vaizdo kamera SONY CCD-TR $411 \mathrm{E}$ ir atlikti fiziniai matavimai. Teoriniams skaičiavimams pritaikytas mechaninio-matematinio modelio kvazistatinis variantas [4] ir sudaryta skaičiuojamoji schema.

\section{Tiriamųjų darbininkų veiklos aprašymas}

Tiriant granito plokščių klojëju fizini krūvị buvo vertinami plokščiu paèmimo rankomis ir ergonomiškomis priemonemis būdai. Visą darbą, susijusị su granito plokščių gabenimu, sudare tokios operacijos:

- pirmiausia nuo viršutinių keturiu paketo eilių (iš viso 16 plokščiụ) du darbininkai ima plokštes ir deda jas ant grindinio šalia paketo;

- mechaniniu kèlikliu (1 pav.) plokštę pakelia, nuneša ir padeda tiksliai i jai skirtą vietą ant jau ịreng- to pagrindo. Plokštėms pakelti nuo pagrindo, kai reikia koreguoti pagrindo aukšti, buvo naudojamas pneumatinis kéliklis (2 pav.).

Kad lengviau būtų pakelti porètajị silikato blokelị, juose buvo išfrezuotos jubbos ( 3 pav.), o silikatinès plytos buvo keliamos iprastiniu būdu - krovejas pasilenkdavo ir imdavo plytas abiem rankomis (4 pav.). Per pamainą silikatinių plytų krovejjas atlieka vidutiniškai iki 4000 tokių pasilenkimų.

\section{Spaudimo jègos L5/S1 diske apskaičiavimas}

Daugelio šalių praktika rodo, kad krovinius keliant rankomis didžiausia tikimybè yra susižaloti diskus, esančius tarp L4/L5 arba L5/S1 stuburo slankstelių. Spaudimo jègai L5/S1 diske apskaičiuoti šiame darbe pritaikytas kroviniu kèlimo rankomis biomechaninio modelio plokščiasis kvazistatinis variantas [4]. Juo remiantis buvo sudaryta skaičiuojamoji schema (5 pav.):

$$
\begin{array}{ll}
F_{m u s c} & - \text { nugaros raumenu jèga, N; } \\
F_{c} & - \text { disko spaudimo jèga, N; } \\
(m g)_{b w}- & \text { viršutinès kūno dalies sunkio jèga, } \\
& \text { turinti ịtakos disko spaudimui, } \mathrm{N} ; \\
(m g)_{1}- & \text { keliamo krovinio sunkio jèga, } \mathrm{N} ; \\
\alpha & - \text { kampas tarp stuburo ir vertikalès, } \\
& \text { žmogui pasilenkus, laipsniais; } \\
b \text { ir } h \quad- & \text { atitinkami pečiai, m. }
\end{array}
$$

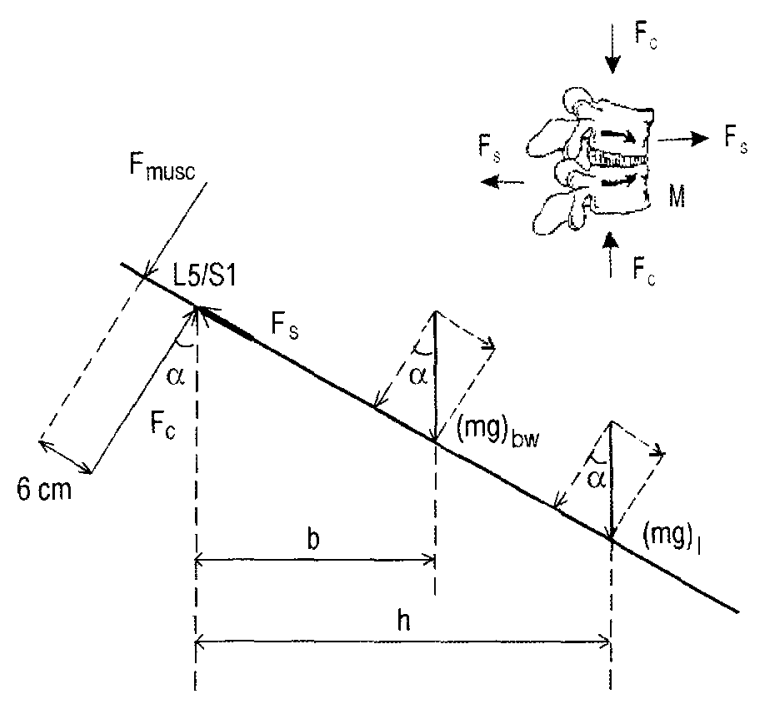

5 pav. Spaudimo jejgos L5/Sl diske skaičiuojamoji schema

Fig 5. Scheme for calculating the $\mathrm{L} 5 / \mathrm{S} 1$ disc compressive force 
Apie nugaros raumenų atstojamosios jègos petị literatūroje samprotaujama skirtingai, nurodoma, kad jo dydis galètų būti nuo $50 \mathrm{~mm}$ iki $75 \mathrm{~mm}$. Šiame darbe peties verté imta $60 \mathrm{~mm}$, nes skaičiavimai yra tik palyginamieji. Remiantis 5 pav. schema, sudarytos lygtys stuburo L5/S1 disko spaudimo jègai apskaičiuoti:

$$
F_{c}=F_{m i s c}+(m g)_{b w} \cos \alpha+(m g)_{1} \cos \alpha,
$$

čia

$$
F_{m u s c}=\frac{(m g)_{b u} b+(m g)_{l} h}{0,06} .
$$

Nagrinejjamu atveju kirpimo jëga $F_{s}$ L5/S1 diske nereikšminga, palyginti su disko spaudimo jèga, todèl jos apskaičiavimas nepateikiamas.

L5/S1 disko spaudimo jèga apskaičiuojama taip. Granito plokščiu klojèjų kūno masé buvo apie $85 \mathrm{~kg}$. Viršutinès kūno dalies masè sudaro $65 \%$ viso kūno masès. Tuomet $(m g)_{b w}=85 \times 0,65 \times 9,81=542,0 \mathrm{~N}$. Kai nugara keliant yra tiesi, $b=18 \mathrm{~cm}$. Granito plokštès projektiniai matmenys yra $(500 \times 500 \times 100) \mathrm{mm}$, faktiškoji masé $-78 \mathrm{~kg}$, ją kelia du klojèjai. Tuomet $(m g)_{l}=(78 \times 9,81) / 2=328,6 \mathrm{~N}$, o petys $\mathrm{h}=35 \mathrm{~cm}$.

Kai klojèjas nuo paketo viršaus plokštes ima rankomis, jo kūnas palinksta $30^{\circ} \mathrm{kampu}$. Šiuo atveju L5/S1 disko spaudimo jèga apskaičiuojama taip:

- nugaros raumenú atstojamoji jèga apskaičiuojama taikant (2) lygtị:

$$
F_{m u s c^{\circ}}=(542 \times 0,18+382,6 \times 0,35) / 0,06=3857,8 \mathrm{~N} \text {, }
$$

- disko spaudimo jèga taikant lygti (1):

$$
F_{c}=3857,8+542 \times 0,866+382,6 \times 0,866=4658,5 \mathrm{~N} .
$$

Šios jègos vertė 6 pav. pažymèta tašku $a$. Taikant šią metodiką apskaičiuotos L5/S1 disko spaudimo jègos, kai granito plokštes rankomis kelia vienas ar du klojejjai ir kai jas kèlikliais kelia du klojejai ( 1 ir 2 pav.). Taip pat L5/S1 disko spaudimo jègos apskaičiuotos porètojo silikato blokeliụ $(300 \times 600 \times 200) \mathrm{mm} \mathrm{mū-}$ rininkams ( 3 pav.) ir silikatinių plytų krovejams (4 pav.), o jụ vertès 6 pav. pažymètos raidemis nuo $a$ iki $i$.

Tyrimai parodè, kad plytų krovejų nugaros sužalojimo rizika labiausiai priklauso nuo pasilenkimu kampo ir dažnio. Be to, dideli fizini diskomfortą krovèjas jaučia ne tik nugaros srityje, bet ir kojose.

Sugretinus 6 pav. pateiktus tyrimų rezultatus (taškai nuo a iki i) ir NIOSH rekomendacijas (tiesès A, B ir C), tenka konstatuoti, kad, atliekant visus aprašytus darbus rankomis, nenaudojant pagalbinių priemonių, stuburo L5/S1 disko apkrovimas viršija rekomenduojama darbinę ribą (DR). Keliant granito plokštę (jos masè $78 \mathrm{~kg}$ ) vienam klojëjui, nors ir nelabai pasilenkus, disko apkrovimas $\left(F_{c}=9915 \mathrm{~N}\right)$ priarteja prie disko stiprumo ribos (jaunam vyrui $F_{c}=12980 \mathrm{~N}$ ). Todèl neleistina vienam klojejjui kilnoti tokias plokštes.

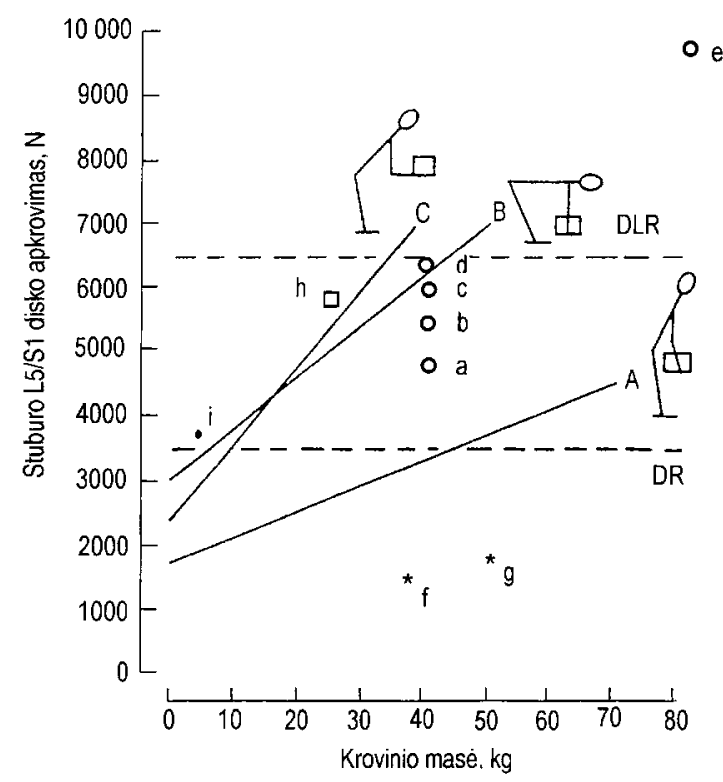

6 pav. Tyrimo rezultatu sugretinimas su JAV Nacionalinio profesinés saugos ir sveikatos instituto (NIOSH) [5] rekomendacijomis: DLR - didžiausia leidžiama riba; DR - darbo riba; taškai a, b, c, d - granitines plokštes du klojèjai kelia rankomis taip, kad jụ kūnas palinksta atitinkamai $30^{\circ}, 45^{\circ}, 60^{\circ}$ ir $90^{\circ} \mathrm{kampu}$; e - tą pati krūvi kelia vienas klojejas; $\mathrm{f}$ - plokšté keliama mechaniniu kèlikliu; g - plokštė keliama pneumatiniu kèlikliu; $\mathrm{h}$ poretojo silikato blokų kèlimas nepalankiomis sąlygomis; i - silikatinès plytos perkraunamos esant nepalankiausiai kūno padečial

Fig 6. Investigation results comparison with NIOSH recommendations [5]. DLR - maximum permissible limit; DR - working limit; a, b, c, d points - manual lifting granite plates by 2 workers with body inclination angle of $30^{\circ}, 45^{\circ}, 60^{\circ}$ and $90^{\circ}$ respectively; e - the same load lifted by a single worker; $f$ - lifting granite plate by a mechanical device; $g$ - lifting granite plate by a pneumatic device; $\mathrm{h}$ - manual lifting porous silicate blocks; i - reloading silicate bricks in a stooped posture

\section{Išvados}

1. Tyrimai ir skaičiavimai parodè, kad vienam klojejjui keliant vienetinius sunkius elementus, tokius kaip šaligatvio plytelès ir natūralaus akmens plokštès, 
yra labai didelé rizika susižaloti stuburo L5/S1 diską (žr. 6 pav. e taškas), nes ji spaudžianti jèga $\left(F_{c}=9935 \mathrm{~N}\right)$ visai priartèja prie disko ribinio stiprumo ( $F_{c}=12980 \mathrm{~N}$ jaunam vyrui). Rizika susižaloti labai sumažèja, kai sunkius elementus kelia du darbininkai ir ši operacija atliekama laikant kuo tiesesnę nugarą.

2. Rizika susižaloti nugaros apatinę dali yra visai nedidelè, kai naudojamos papildomos ergonomiškos techninès priemonés (5 pav. $f$ ir $g$ taškai), kurios nesumažina keliamo elemento svorio, o naudojant pneumatinị kèlikli ji dar ir padidina, tačiau klojejas gali dirbti laikydamas nugarą tiesią, nepasilenkęs, taigi iki nulio sumažinami momentai, veikiantys labiausiai apkrautą L5/ S1 diską.

3. Statybos industrijoje reikia plačiau diegti technologijas, leidžiančias porètojo silikato blokelius patogiai paimti ( 3 pav.). Jeigu blokeliuose nèra specialiu išèmų, mūrininkas turi žemiau pasilenkti. Taigi padidèja momentai, didinantys L5/S1 disko spaudima, ir padideja rizika susižaloti ( 6 pav. h taškas).

4. Rizika silikatinių plytų krovejjams susižaloti nugaros apatinę dali padideja dèl dažnų žemų pasilenkimụ. Todèl būtina ịdiegti tokias ergonomiškas technines priemones, kad darbininkui, kraunančiam plytas, reikètų tik šiek tiek pasilenkti, pavyzdžiui, naudoti darbo plokštumos pastovaus aukščio laikiklius.

\section{Literatūra}

1. J. D. G. Troup and F. C. Edwards. Manual Handling and lifting. An Information and Literature Review with Special Reference to the Back. The Health and Safety Executive (London: HMSO), 1985. 153 p.

2. H. Janik, Antje Kankel, E. Münzberger and Schultz. Changes of body height in stooped lifting // Proceedings of the 13th Triennial congress of the International Ergonomics Association, Vol 3, Tempere, Finland, 1997, p. 534-536.

3. Krovinių kèlimo rankomis bendrieji nuostatai // Valstybès žinios, 1998, Nr. 79-2242, p. 52-56.

4. D. B. Chaffin and G. B. J. Andersson. Occupational Biomechanics (2 nd. ed.). New York: Wiley, 1991. 454 p.
5. National Institute for Occupational Safety and Health (NIOSH). Work Practices Guide for Manual lifting. Cincinnati, 1981. $183 \mathrm{p}$.

Iteikta 20010221

\section{ERGONOMIC ASSESSMENT OF MANUAL BUILD- ING WORK ASSOCIATED WITH LIFTING TASKS}

\section{K. A. Kaminskas}

\section{Summary}

The purpose of these studies is to reduce the amout of low back pain as well as work injuries. Low back pain is more likely to occur if the load exceeds the worker's physical capabilities. In this paper, biomechanical criterion was based on calculating the compressive forces in the $\mathrm{L} 5 / \mathrm{S} 1$ disc (Eqs (1), (2)).

Three types of activity were taken into consideration. First, manual lifting granite plates $(500 \times 500 \times 100 \mathrm{~mm})$ with and without special devices (Figs 1,2). Second manual lifting porous silicate blocks $(300 \times 600 \times 200 \mathrm{~mm})$. Third, manual lifting silicate brick in stooped postures.

The investigation results presented in Fig 6 show clear benefits of ergonomic solutions for manual lifting heavy construction elements.

The risk for back injuries becomes quite insignificant when ergonomic lifting devices are used (Fig 6 point $f$ and $g$ ). These devices do not reduce the weight of lifted elements, but in case of a pneumatic device the total lifting weight is considerably increased, but the positive effect is achieved due to reducing moments because workers perform the task with a straight back.

The reloaders of bricks usully feel back pain due to extreme repetitive bending of the back.

Kazys Algirdas KAMINSKAS. PhD, Assoc Professor. Dept of Labour Safety and Fire Protection, Vilnius Gediminas Technical University (VGTU), Sauletekio al. 11, LT-2040 Vilnius, Lithuania. E-mail: algirdas.kaminskas@st.vtu.1t

Graduate of Kaunas Politechnical Institute (presently KTU) (1966, civil engineer). PhD (1975). Research visits: Moscow Civil Engineering Institute (Russia, 1976), King's College University of London (UK, 1979-1980), National Institute for Working Life (Sweden, 1995), Central Institute for Labor Protection (Poland, 1996). Author and co-author of a number of papers. Research interests: ergonomics in construction and occupational safety. 